\title{
ДОЗИМЕТРИЧЕСКАЯ ОЦЕНКА ЭФФЕКТА ОТ ИМПУЛЬСНОГО ЭЛЕКТРИЧЕСКОГО РАЗРЯДА В ВОДНОЙ СРЕДЕ
}

Импульсный электрический разряд высокого напряжения в жидкости представляет собой поток (или несколько потоков) заряженных частиц - электронов и продуктов ионизации среды, т. е. то, что называют «низкотемпературной» плазмой. При этом в системе возникают и на неє воздействуют следующие эффекты: ионизация и разложение молекул среды - непосредственно в плазме и на границе с ней; высокая температура - до нескольких десятков тысяч градусов - в зоне разряда; мощное световое излучение; ударно-волновое (механическое) воздействие значительной силы; ультразвуковое пэле с широким спектром частот. Можно ожидать также возникновения явлений электрофореза и кавитации в объеме [1-3].

До настоящего времени в литературе рассматривались только ударно-механический эффект и его воздействие на тела и материалы в «реакционном» объеме, примыкающем к зоне разряда []. Эффект же от воздействия остальных указанных выше явлений на жидкую среду (воду) и растворенные или взвешенные в ней вещества, а также механизм протекающих в воде или растворе физико-химических процессов не привлекали внимания исследователей и не получили должной оценки.

Под влиянием описанных составляющих комплексного процесса (за исключением, пожалуй, ударно-механического воздействия) должен возникать ряд физико-химических эффектов, приводящих в конечном счете к ионизации и разложению молекул воды, сольватированию заряженных частиц (электронов) и образованию «первичных» радикальных продуктов (гидроксил, водород), а также «вторичных» молекулярных продуктов их взаимодействия (молекулярный водород, перекись водорода). Суммарный эффект от такого воздействия должен быть сходен с результатами обработки водной среды проникающим излучением [5-7, 11].

В настоящем сообщении в сжатом виде приведен обзор результатов экспериментального исследования в этом направлении, предпринятого с цельо приближенной оценки результатов физико-химического воздействия на водную среду «электроняпульсной» обработки и создания общего представзения о сущности протекающих физнкохимических процессов.

\section{Методика исследования}

Экспериментальное исследование проведено в герметичном бронзовом реакторе цилиндрической формы диаметром в свету 120 мм, высотой внутренней части 240 мл и суммарным объемом реакционной зоны 3000 мл. Через верхнюю крышку реактора, в специальном изоляторе, вводится вертикальный верхний электрод (латунный). Второй электрод вставлен в днище реактора. Расстояние между электродами во всех опытах равно 15 мм. В реакторе предусмотрены герметизированные отверстия для фото- 

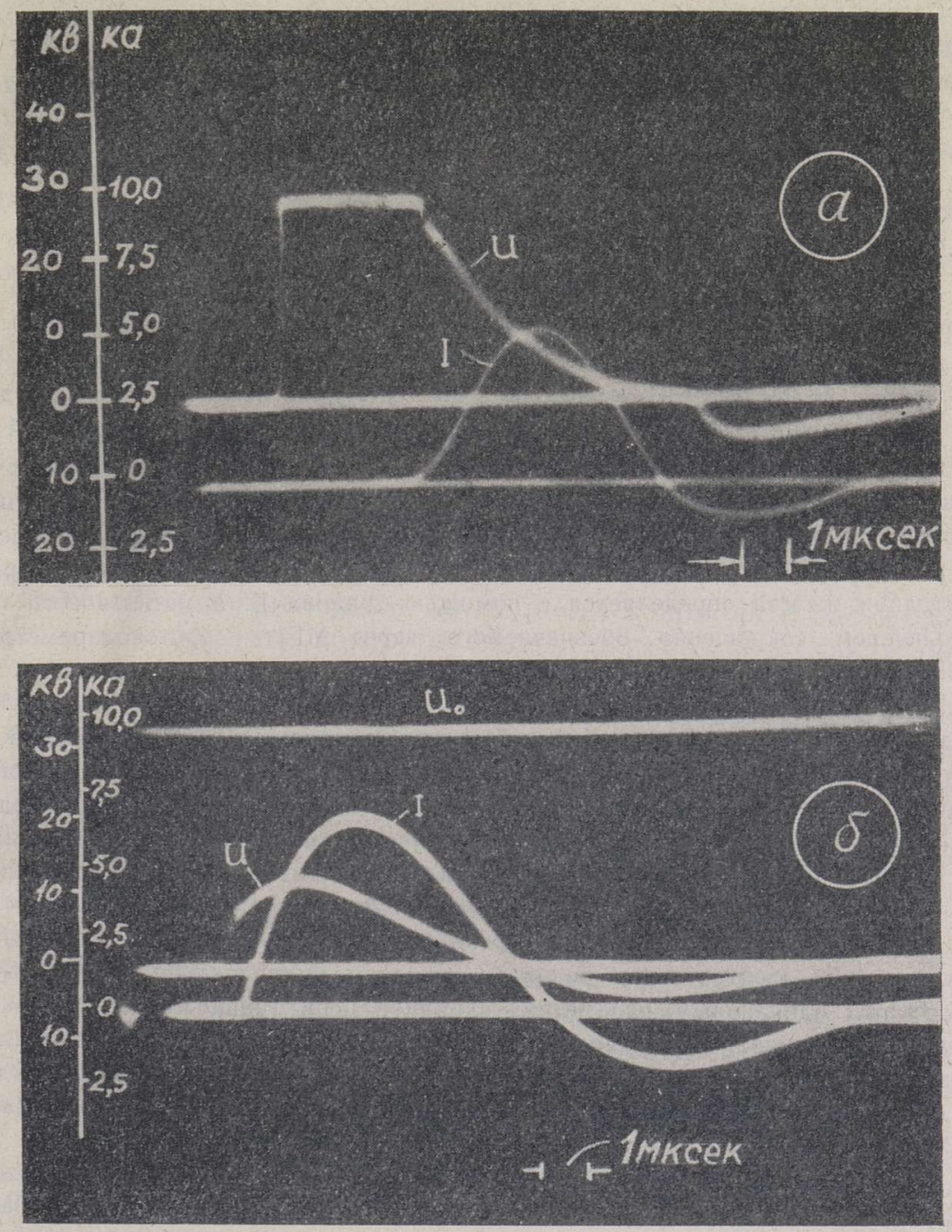

Рис. 1. Осциллограммы напряжения и тока при электрическом разряде в кислой (ферросульфатная система - $a$ ) и нейтральной (раствор метиленового голубого - б) среде при $U=30 \kappa в$; $c=0,6$ мкф; $l=15$ мм. $a$. Кривые сняты при электропроводности раствора $\sigma=0,1 \mathcal{M}^{-1} \cdot c M^{-1}$. Пробой отсутствует; стекание заряда конденсатора $\frac{u c_{0}^{2}}{2}$ через электролит. б. Кривые сняты при электропроводности раствора $\sigma=10^{-4} \quad M^{-1} \cdot C M^{-1}$. Пробой разрядного промежутка.

съемки и визуальных наблюдений, сбора газа и отбора проб жидкости. Напряжение подается в систему из батареи конденсаторов соответствующей емкости. Более детально устройство экспериментальной установки описано в сообщении $\left[{ }^{2}\right]$.

В реактор вводится 1100 мл испытуемой жидкости. Объем заполненного воздухом пространства составляет $1700 \mathrm{M}$. Таким образом создаются условия для непрерывной аэрации системы.

Ход процесса контролируется путем осциллографирования тока и напряжения на двухлучевом приборе типа ОK-17, измерения эффективной величины сопротивления среды между электродами и изучения электрофизических свойств отбираемых проб жид- 
кости. Сигналы напряжения и тока, подаваемые непосредственно на пластины осциллографа, снимаются с емкостного делителя напряжения и с безындукционных шунтов. Обработка осциллограмм дает возможность рассчитать характеристики разряда и определить изменение во времени мгновенных значений мощности; сопротивления канала разряда; энергии, выделяющейся в зоне разряда; коэффициента полезного действия системы $\eta=\frac{W_{T / 2}}{W_{m}}$, где $W_{T / 2}$ - энергия, выделившаяся за половину первого периода, а $W_{m}=\frac{c u_{0}^{2}}{2}-$ энергия, запасенная в конденсаторах.

Для оценки физико-химических процессов, происходящих при радиолизе водной среды, обычно применяются так наз. химические дозиметрические системы [5-7, 8]. Нами использованы дзе наиболее изученные системы: 1) ферросульфатная (так наз. дозиметр Фрике), которая представляет собой $10^{-3}$ M раствор соли Мора в $0,8 \mathrm{~N}$ серной кислоте с добавкой 0,06 г/ $\Omega$ хлористого натрия, и 2) нейтральный водный раствор метиленового голубого в концентрации около $5 \cdot 10^{-5} \mathrm{M}$. В первом случае о протекающих реакциях судят по выходу железа, окисленного до трехвалентных ионов (в расчете на 100 эв подведенной в систему энергии), во втором - по изменению окраски раствора. Концентрация железа определяется с помощью трилона Б, а метиленового голубого (в дальнейшем сокрашенно. обозначаемого через МГ) - фотоколориметрическим методом.

Дополнительные эксперименты проведены с дистиллированной водой без добавок с определением выхода молекулярных продуктов: водорода - в газе, окислов азота и перекиси водорода - в воде. Нсследование проведено с изменением одного лишь электрофизического параметра - емкости системы в ударе - в широких пределах от 0,0044 до 0,$1 ; 0,6 ; 1,2$ и 2,4 мкф. При заданном напряжении эта величина определяет энергию и длительность одного разряда, то есть мощность дозы. Общая доза определяется в каждом случае числом поданных нмпульсов.

На рис. 1 а и б для примера представлены характерные осциллограммы тока и напряжения при электрическом разряде в кислом и нейтральном дозиметрических растворах при одинаковых параметрах зарядной цепи (напряжение $30 \kappa 8$, емкость 0,6 лкф). Зафиксированные в характеристике различия разряда обусловлены электрофизическими свойствами изученных сред [9]. Более подробно результаты электрофизических исследований изложены в специальном сообщении (см. наст. номер журнала, стр. $457-464)$.

В результате неизбежной в подобного рода системах эррозии электродов [10] в раствор переходит некотор®е количество меди, немедленно вступающей во взаимодействие с продуктами разложения воды. Специальными опытами нами установлено, что выход меди в нейтральной системе примерно пропорционален количеству подведенной энергии и в пределах изменения емкости от 0,1 до 1,2 мкф составляет от 0,5 до 3,1·10-25 гат/л в расчете на каждые 100 эв. В кислой среде, вследствие изменения электрофизических параметров процесса, он снижен примерно в 2-3 раза.

\section{РЕЗУЛЬТАТЫ ИССЛЕДОВАНИЯ И ИХ ОБСУЖДЕНИЕ.}

\section{Результаты дозиметрического исследования в кислой ферросульфатной системе}

Исследования с помощью дозиметра Фрике дают возможность оценить окислительный потенциал процесса воздействия на воду ионизирующих агентов. Материальный баланс процесса радиолиза воды онисывается уравнением

$$
G_{\mathrm{H}}+2 G_{\mathrm{H}_{2}}=G_{\mathrm{OH}}+2 G_{\mathrm{H}_{2} \mathrm{O}_{2}}
$$


где $G_{x}$ - радиационный выход продукта $x$, то есть число атомов, молекул, радикалов или ионов в расчете на 100 эв подведенной энергии. Экспериментально установлено $\left[5,6,{ }^{11}\right]$, что радиационный выход молекулярного водорода в кислой или нейтральной среде неизменно составляет около 0,45 молекулы на 100 әв при радиолизе с мощностью дозы до $10^{18}$ эв/мл -сек. Выход же продукта радиационного окисления в системе Фрике (трехвалентного иона железа) определяется наличием или отсутствием растворенного в воде кислорода. По данным $[5,6,11]$, при тех же мощностях дозы он составляет для дезаэрированной среды

$$
G\left(\mathrm{Fe}^{3+}\right)=G_{\mathrm{H}}+G_{\mathrm{OH}}+2 G_{\mathrm{H}_{2} \mathrm{O}_{2}}=8,2
$$

а в аэрированной системе достигает

$$
\hat{G}\left(\mathrm{Fe}^{3+}\right)=3 G_{\mathrm{H}}+G_{\mathrm{OH}}+2 G_{\mathrm{H}_{2} \mathrm{O}_{2}}=15,5,
$$

что объясняется взаимодействием атомарного водорода с растворенным кислородом, в результате которого образуется дополнительная порция перекиси водорода.

С увеличением мощности дозы до $10^{21} \div 10^{23}$ әв/м $\cdot$ сек выход продуктов окисления закономерно снижается. При значениях ее, близких к указанному верхнему пределу, выход трехвалентного железа уменьшается по сравнению с величиной кз уравнений (2) или (3) примерно вдвое $\left[{ }^{11}, 12\right]$. Это обстоятельство следует учесть при оценке полученных экспериментальных результатов, поскольку условная мощность дозы при описанном изменении емкости колеблется в пределах от 0,2 до $2,65 \cdot 10^{23} э в / м \Omega \cdot с е \kappa$. По последним данным [11], добавка в систему Фрике хлористого натрия, который при низкой мощности дозы предохраняет от искажающего воздействия органических примесей, при высокой мощности дозы ведет к снижению выхода трехвалентного железа (примерно на $15 \%$ от возможного). Активная роль примеси ионов меди, окисление которых происходит с более высокой скоростью, чем двухвалентного железа, может быть ориентировочно оценена по данным работы [13]. В ней дана зависимость выхода окисленного железа при радиолизе системы Фрике от изменения концентрации ионов меди в пределах от $10^{-6}$ до $1 \mathrm{M}$.

На рис. 2 представлена кривая, построенная в логарифмических координатах, для зависимости выхода окисленного железа (количество ионов на 100 эв подведенной энергии) от дозы. По своему характеру эта зависимость сходна с закономерностями для радиолиза системы Фрике [11. 13]. Характерным является резкое снижение выхода трехвалентного железа с увеличением дозы, по-

Рис. 2. Зависимость выхода окисленного трехвалентного железа (ионы на 100 эв подведенной энергии) от дозы.

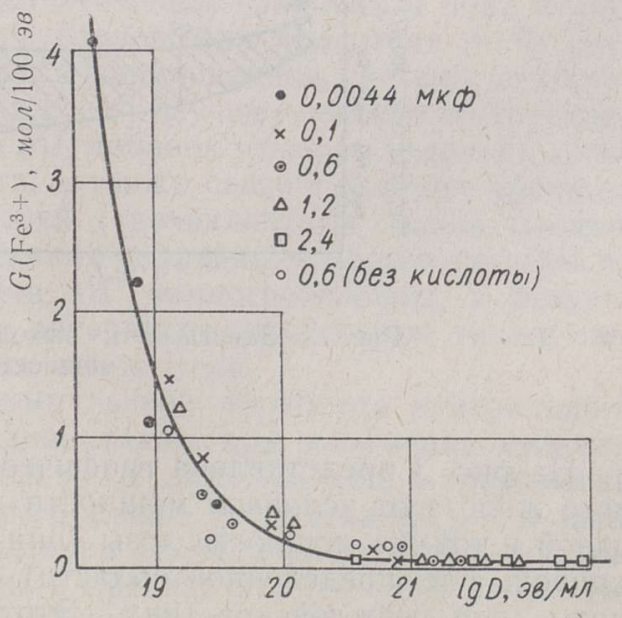

10 ENSV TA Toimetised F-3 66 
видимому, обусловленное в значительной мере нарастанием концентрации ионов меди в растворе.

На основе цитированных литературных данных и результатов эксперимента можно ориентировочно оценить «химический к. п. д.» электроимпульсного процесса - по соотношению фактического выхода окисленного железа и теоретического показателя для аэрированной системы,

Таблища I

Химический коэффициент полезного действия процесса окисления в ферросульфатной кислой системе

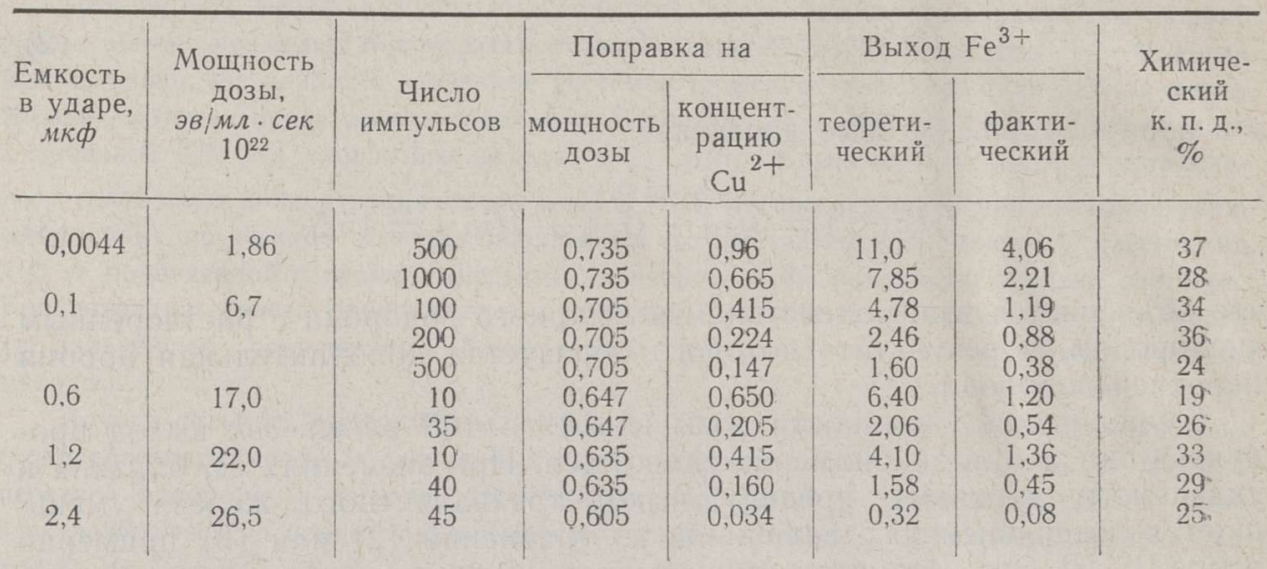

с учетом поправок на мощность дозы, концентрацию хлористого натрия и порядок величины содержания ионов меди в растворе. Результаты такого расчета для некоторых экспериментальных точек приведены в табл. 1. Они свидетельствуют о том, что до $35 \%$ подводимой в среду энергии расходуется эффективно на осуществление реакций окисления В: изучаемой дозиметрической системе.

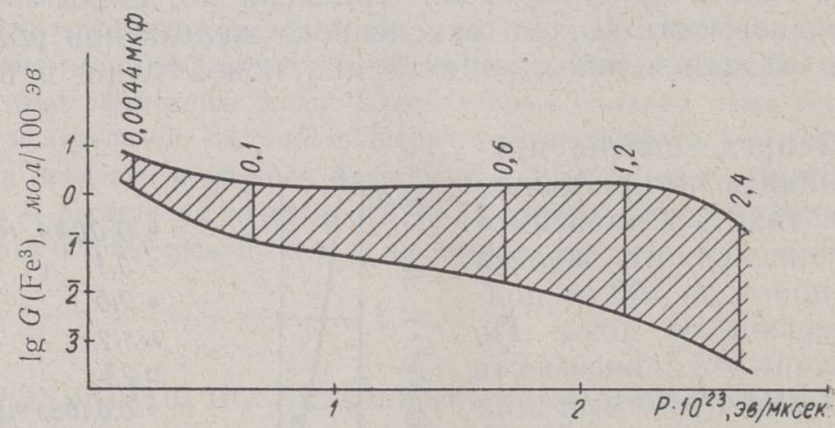

Рис. 3. Зависимость выхода окисленного железа от мощности дозы.

На рис. 3 представлена графически зависимость выхода трехвалентного железа от условной мощности дозы. Известный разброс точек для одной и той же мощности дозы (они хорошо укладываются не на одной кривой, а в определенной области) обусловлен различиями в значении дозы для каждой из них. Этот график сходен с кривой для 
аналогичной зависимости из цитированной работы $\left.{ }^{11}\right]$. Из него следует, что с повышением мощности дозы до $2,65 \cdot 10^{23}$ эв/м $\cdot$ сек выход продуктов окисления начинает заметно снижаться. Сходное заключение вытекает и из рассмотрения данных табл. 2 - эффективность процесса окисления несколько снижается при предельной мощности дозы.

Таблица 2

Результаты эксперимента с аэрированной нейтральной водой (Условная мощность дозы $3,6 \cdot 10^{23}$ эв/мл секк)

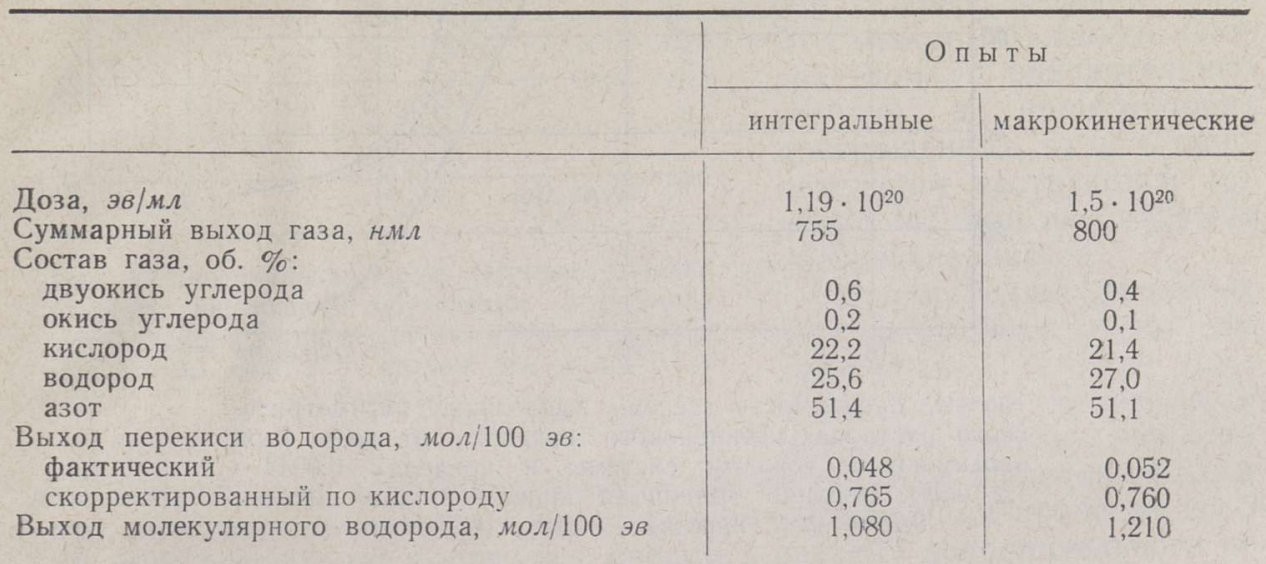

\section{Результаты дозиметрического исследования нейтральной системы вода-метиленовый голубой}

Дозиметрический раствор МГ в воде обычно используется для оценки роли восстановительных реакций при радиолизе воды. На восстановление одной молекулы $M \Gamma$ до бесцветной лейкоформы расходуется два атома водорода. Обработка дезаэрированной системы гамма-излучением дает обратимое выцветание раствора. Однако при длительном облучении и последующем воздействии кислорода окраска восстанавливается лишь частично, что принято объяснять сложным и пока неизученным процессом радиолитического разложения красителя $\left[{ }^{5}, 6\right]$. Воспроизводимость результатов обработки аэрированной системы недостаточно удовлетворительна. В работах $\left[{ }^{14,}{ }^{15}\right]$ изучено сенсибилизирующее действие на процесс восстановления МГ добавок глюкозы и других легко окисляющихся органических веществ, а также сенсибилизация процесса окисления добавками восстановителей (трехвалентных ионов железа, кислорода). Работа по изучению влияния величины и мощности дозы на обратимое обесцвечивание растворов МГ немногочисленны, а результаты их - противоречивы $\left[{ }^{14}, 16\right]$. В литературе отсутствуют также сведения о влиянии на процесс добавки ионов меди.

Исследование процесса электроимпульсной обработки нейтрального аэрированного раствора МГ проведено также при изменении емкости системы в ударе от 0,0044 до 0,$1 ; 0,6$ и 1,2 мкф. На рис. 4 графически приведены основные результаты этого цикла исследований - в виде зависимости степени выцветания раствора (концентрация МГ в процентах от исходной) от величины дозы в пределах $10^{19}-10^{21}$ эв/мл. На рисунке показана область, в которую укладывается семейство идентич- 
ных по своему характеру кривых, причем конечные точки, относящиеся к дозе свыше $10^{21} ә в / \mu \Omega$, соответствуют кривым для емкости в ударе 0,0044 (верхняя граница полосы) и 0,6 мкф (нижняя ее граница).

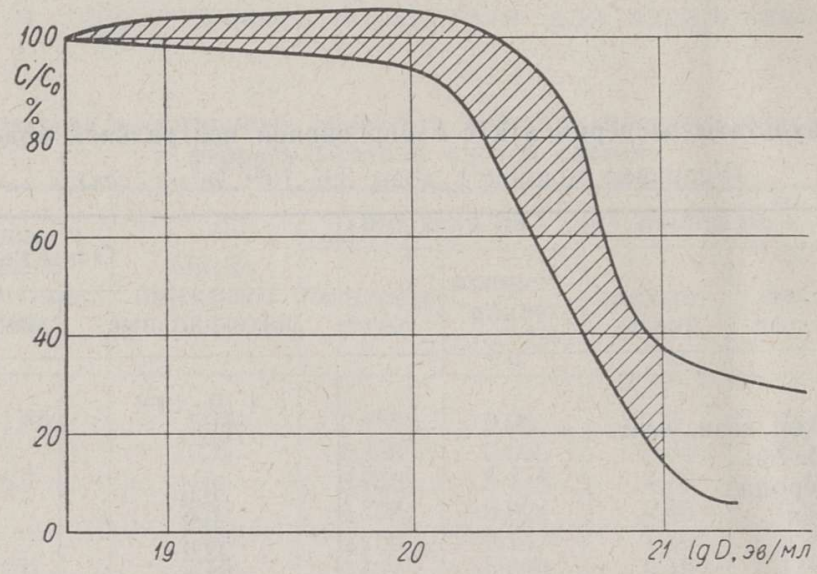

Рис. 4. Зависимость степени выцветания дозиметрического раствора метиленового голубого от дозы (при варьировании емкости системы в пределах 0,00441,2 мкф). Верхняя граничная кривая - для емкости 0,0044 мкф, нижняя - для $c=0,6$ мкф.

График рис. 4 можно разбить на два основных участка. Первый из них соответствует величине дозы от $10^{19}$ дс $3 \div 4 \cdot 10^{20}$ әв/ $/ \Omega$. В этой области выцветание раствора практически не наблюдается. Ориентировочный подсчет потенциального запаса продуктов разложения воды, основанный на литературных данных с учетом к. п. д. процесса до $50 \%$ [6], показывает, что запас окислителей превосходит ресурсы восстановителя по меньшей мере в два раза, а при данном количестве подведенной энергии каждая молекула МГ может подвергнуться восстановлению и окислению не менее 100 раз. Этими обстоятельствами и объясняется отсутствие обратимого выцветания в условиях проведенного эксперимента.

На втором участке, начиная с указанной величины дозы, наступает интенсивное необратимое обесцвечивание раствора, причем выход обесцвеченного продукта невелик - порядка 10-3 молекулы на 100 әв и изменяется в зависимости от электрофизических параметров процесса. Подсчеты показывают, что для изменения концентрации МГ в растворе из-за необратимого его разложения, обнаруживаемого фотоколориметрическим способом, требуется доза порядка $2 \div 4 \cdot 10^{20}$ эв/м $\Omega$. Этим и объясняется частично наличие перегиба (то есть некоторого «критического» порога) в макрокинетических кривых, изображенных на рис. 4. Тем не менее, во всех случаях начиная с указанной дозы интенсивность необратимого обесцвечивания МГ возрастает. Причина этого явления может быть качественно выявлена в итоге экспериментов с сенсибилизацией процессов окисления или восстановления. На рис. 5 изображены кривые, характеризующие процесс обесцвечивания МГ в обычных условиях опыта при емкости 0,1 мкф и для случая добавки глюкозы в концентрации $0,01 \mathrm{M}$ с сенсибилизацией реакции восстановления. Рассмотрение графика показывает, что при дозе, которая в обычном растворе 


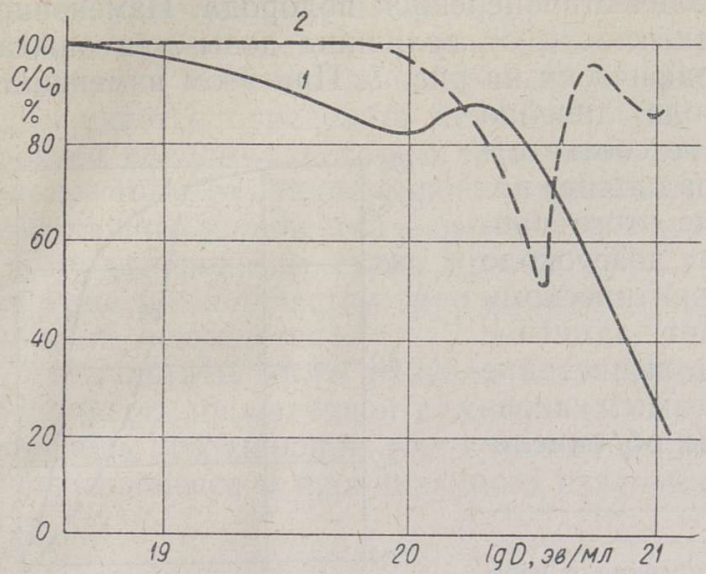

Рис. 5. Сенсибилизирующее действие добавки глюкозы на процесс обратимого выцветания метиленового голубого: 1 - обычная кривая при $c=0,1$ мкф; 2 - крнвая для опыта с добавкой. приводит к активному необратимому обесцвечиванию, происходит заметное (до $50 \%$ ) обратимое выцветание. По израсходовании запаса акцептора окислителей окраска раствора восстанавливается, а затем наступает необратимое обесцвечивание со значительным сдвигом к более высокой дозе. Это можно объяснить лишь участием окислительных агентов в происходящих превращениях, то есть окислительной деструкцией молекул МГ при необратимом обесцвечивании.

На рис. 6 даны аналогичные кривые для случая сенсибилизации реакций окисления путем непрерывной продувки системы кислородом в процессе ее электроимпульсной обработки. Как и следовало ожидать, они свидетельствуют о некоторой интенсификации процесса необратимого выцветания раствора с вводом в систему дополнительного количества окислителя. Приведенные факты приводят также к заключению, что в процессе окислительной деструкции МГ участвуют не только гидроксильные радикалы, но и «вторичный» молекулярный продукт перекись водорода, выход которой существенно возрастает при насыщении раствора кислородом.

Таким образом, в результате исследования с дозиметрическим раствором метиленового голубого удается установить закономерности реакций окисления и восстановления, качественно сходные с известными в радиационной химии.

\section{Результаты исследования с нейтральной аэрированной водой}

Опыты с дистиллированной нейтральной водой, насыщенной воздухом, проведены в двух циклах, каждый из которых включает две серии. Первый цикл экспериментов поставлен в том же бронзовом реакторе при емкости в ударе 0,$1 ; 0,6$ и 1,2 мкф, т. е. при условной мощности дозы от 1,6 до 1,3 и $0,7 \cdot 10^{23}$ эв/м $\cdot$ сек. В первой серии произведен систематический отбор проб жидкости для химического исследования, во второй поставлен непрерывный эксперимент со сбором и исследованием состава выделяющегося газа (интегральные опыты).

Результаты кинетических опытов показывают, что даже при наименьшей мощности дозы в воде удается обнаружить продукт окисления азота растворенного воздуха - нитрит ион - в концентрации от 0,01 до 0,1 мг/л. С доведением дозы до $10^{21}$ эв/мл концентрация нитрит аниона существенно возрастает - до $0,6 \div 2$ ма/ $\Omega$ (погрешность в определении вызвана сильным помутнением раствора из-за перехода в систему окислов меди). Аналогичная картина наблюдается и при увеличении мощности дозы $(c=0,6 м \kappa \phi)$. Начиная с дозы около $4 \div 7 \cdot 10^{19}$ эв/м $\Omega$ в обоих случаях в растворе удается обнаружить сперва следы, а затем поддаю- 
щееся точному определению количество перекиси водорода. Изменение концентрации последней в зависимости от величины дозы для опыта при $c=0,6$ мкф изображено графически на рис. 7. При этом изменение конгентрации перекиси водорода линейно связано с увеличением дозы, что соответствует данным для импульсного радиолиза воды $[12,17]$. Заметное накопление этого продукта в системе соответствует дозе около $3 \div 4 \cdot 10^{20}$ эв/мл, т. е. тому критическому порогу, при котором наступает заметное и интенсивное необратимое выцветание метиленового голубого. Тем самым вновь подтверждается предположение об окисли-

Рис. 6. Сенсибилизация процесса окисления с необратимым обесцвечиванием метиленового голубого при добавке в системе кислорода (кривая 2); емкость в ударе - 0,6 мкф.

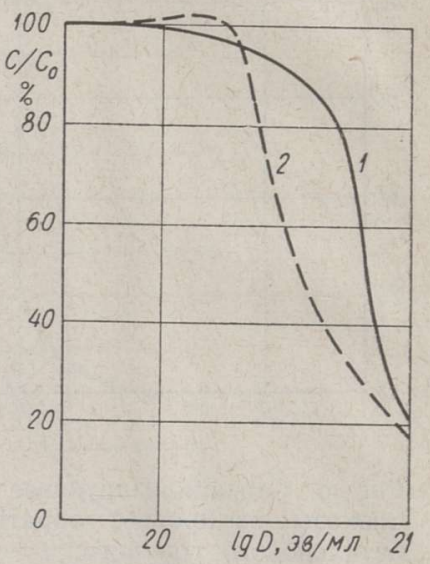

тельной деструкции МГ при необратимом выцветании, вызванной вмешательством не только гидроксильных радикалов, но и такого активного, но медленно действующего окислителя, как перекись водорода.

В результате интегральных опытов установлено значительное содержание в газе не только водорода, но и окислов углерода, которое может быть обусловлено частичной деструкцией и сгоранием изолирующего материала электродов - каучука. В связи с этим, а также для элиминации активных акцепторов продуктов разложения воды - ионов меди, нами поставлен второй цикл опытов с дистиллированной водой - в реакторе, выполненном из нержавеющей $\begin{array}{cc}\text { Рис. 7. Изменение концентращии пере- } & \text { стали, и в условиях, когда устра- } \\ \text { киси водорода с увеличением дозы } & \text { нена деструкция изолирующего ма- } \\ \text { при обработке дистиллированной } & \text { териала Электродов. Эксперимент } \\ \text { воды. } & \text { выполнен также в двух сериях, т. е. } \\ & \text { с интегральными и кинетическими } \\ & \end{array}$ $\begin{array}{cc}\text { Рис. 7. Изменение концентращии пере- } & \text { стали, и в условиях, когда устра- } \\ \text { киси водорода с увеличением дозы } & \text { нена деструкция изолирующего ма- } \\ \text { при обработке дистиллированной } & \text { териала Электродов. Эксперимент } \\ \text { воды. } & \text { выполнен также в двух сериях, т. е. } \\ & \text { с интегральными и кинетическими } \\ & \end{array}$ $\begin{array}{cc}\text { Рис. 7. Изменение концентращии пере- } & \text { стали, и в условиях, когда устра- } \\ \text { киси водорода с увеличением дозы } & \text { нена деструкция изолирующего ма- } \\ \text { при обработке дистиллированной } & \text { териала Электродов. Эксперимент } \\ \text { воды. } & \text { выполнен также в двух сериях, т. е. } \\ & \text { с интегральными и кинетическими } \\ & \end{array}$ $\begin{array}{cc}\text { Рис. 7. Изменение концентращии пере- } & \text { стали, и в условиях, когда устра- } \\ \text { киси водорода с увеличением дозы } & \text { нена деструкіия изолирующего ма- } \\ \text { при обработке дистиллированной } & \text { териала Электродов. Эксперимент } \\ \text { воды. } & \text { выполнен также в двух сериях, т. е. } \\ & \text { с интегральными и кинетическими } \\ & \end{array}$ $\begin{array}{cc}\text { Рис. 7. Изменение концентращии пере- } & \text { стали, и в условиях, когда устра- } \\ \text { киси водорода с увеличением дозы } & \text { нена деструкіия изолирующего ма- } \\ \text { при обработке дистиллированной } & \text { териала Электродов. Эксперимент } \\ \text { воды. } & \text { выполнен также в двух сериях, т. е. } \\ & \text { с интегральными и кинетическими } \\ & \end{array}$ опытами при условной мощности дозы около $3,6 \cdot 10^{23}$ эв/мл (такая мощ-
ность дозы дает возможность для сравнения полученных данных с результатами импульсного радиолиза воды - см. $[12,17])$. Полученные даннье приведены в табл. 2. Добавим, что в кинетических опытах установлена таже линейная зависимость концентрации перекиси водорода в растворе от дозы, что и изображена на рис. 7.

Данные табл. 2 показывают, что выход молекулярного водорода около 1,1 мол/100 эв - составляет примерно 50 - $60 \%$ от показателя, определенного при импульсном радиолизе воды при сходной мощности дозы [17]; однако выход перекиси водорода, растворенной в воде, существенно ниже аналогичного показателя при радиолизе $(1,98$ мол/100 эв). Состав же выделившегося газа (см. табл. 2) свидетельствует о значительном избытке в нем кислорода. Это позволяет предположить, что 
некоторая часть перекиси водорода подвергается разложению под мощным световым воздействием, сопровождающим электрические разряды в жидкости. На основании данных по выходу избыточного кислорода в газе удается определить истинный, или скорректированный, выход перекиси водорода, который составляет примерно 0,76 мол/100 э6, то есть около $40 \%$ от радиационно-химического показателя. Наличие в газе небольшого количества окислов углерода определяется переходом в систему углерода из стали при эррозии электродов (баланс углерода в системе по количеству эрродированной стали и содержанию его в газе хорошо замыкается).

Результаты этого раздела исследований вновь подтверждают справедливость проведенной нами аналогии в механизме физико-химичєских явлений, протекающих при воздействии на водную среду электроимпульсного процесса и проникающего излучения с большой мощностью дозы.

\section{Заключение}

Исследование воздействия электроимпульсной обработки на химические дозиметрические системы и нейтральную аэрированную воду показало, что в этом случае в водной среде протекают сложные физикохимические процессы, качественно сходные по конечному эффекту с явлениями при импульсном радиолизе с высокой мощностью дозы. «Химический к. П. д.» реакций окисления и восстановления, установленный для изученных систем, в пределе достигает $30-50 \%$ по отношению к эффекту от радиационно-химического процесса.

\section{Л И ТЕ Р А Т У Р А}

1. Пробой диэлектриков и полупроводников (сб. докладов), М.-Л., 1964.

2. Гу бергриц М. Я., Бродская Б. Х., Па альме Л. П., Куйв К. А. Изв. АН ЭССР. Сер. физ.-матем. и техн. наук, 10, № 3, 234 (1961).

3. Б а лыг и н И. Е., Электрическая прочность жидких диэлектриков, М.-Л., 1964.

4. Ю ткин Л. А., Электрогидравлическое дробление, Л., 1959.

5. В ер е щи нски й И. В., П ика ев А. К., Введение в радиационную химию, М., 1963.

6. Аллен А. О., Радиационная химия воды и водных растворов, М., 1963.

7. Полак Л. С. (ред.), Кинетика и термодинамика химических реакций в низкотемпературной плазме, М., 1965.

8. К а б а к чи А. М., Г р а мі о лин В. А., Усп. химии, 27, № 4, 459 (1958).

9. Мельников Н. П., Остороумов Г. А., Стояк М. Ю., Сб. Пробой диэлектриков и полупроводников. М.-Л., 1964 , с. 246.

10. По бе жим ов Н. Ф., Ч епиков А. Т., Сб. Пробой диэлектриков и полупроводников, М.-Л., 1964, с. 236.

11. Пика ев А. Қ., Глаз уно в П. Я., Тр. Ташкентской конф. по мирному использованию атомной энергии 1959 , т. 1 , Ташкент, 1961 , с. 354.

12. Anders on A. K., J. Phys. Chem., 66, No. 1, 180 (1962).

13. Чернов а А. И., Орехов В. Д., Проскурнин М. А., Ж. физ. химии, т. 32 , № 12,2843 (1958).

14. Орехов В. Д., Чернова А. Н., Проскурнин М. А., Сб. работ по радиационной химии, М., 1955 , с. 85.

15. Орехов В. Д., 3 а п сохов а А. А., Тр. Ташкентской конф. по мирному использованию атомной энергии 1959, т. 1, Ташкент, 1961 , с. 465.

16. С в аллоу А., Радиационная химия органических соединений, М., 1963.

17. Anderson A. K., Hart E. J., J. Phys. Chem. 66, No. 1, 70 (1962). 
M. GUBERGRITS, B. BRODSKAJA, L. PAALME

\section{KÕRGEPINGE IMPULSSLAHENDUSE TOIME VESILAHUSTELE JA SELLE DOSIMEETRILINE HINDAMINE}

Kõrgepinge impulssiahenduse toimet vesilahustele hinnati radiatsioonikeemias laialdaselt kasutatavate dosimeetriliste süsteemide, nagu raud(II) sulfaadi väävelhappelise lahuse (nn. Fricke dosimeeter), metüleensinise vesilahuse ja destilleeritud vee abil erinevate impulsi parameetrite juures $(0,0044-2,4 \mu \mathrm{F} ; 30 \mathrm{kV})$.

Katsed näitasid, et kôrgepinge impulsslahenduse mõjul (doosi võimsuse juures $10^{23} \mathrm{eV} / \mathrm{ml} \cdot \mathrm{s}$ ) toimuvad vesilahustes protsessid, mis oma löppeffekti poolest sarnanevad radiolüüsiga.

Körgepinge impulsslahendusprotsessi «keemiline kasutegur» kõigub 30-40\% piires.

M. GUBERGRITS, B. BRODSKAYA, L. PAALME

\section{THE DOSIMETRIC EVALUATION OF ELECTRICAL PULSE DISCHARGE EFFECT UPON AQUEOUS MEDIA}

The total physico-chemical effect of high pressure pulse-discharge action on liquid (aqueous) media is evaluated by means of some dosimetric chemical systems widely used in radiation chemistry. The experimental investigation deals with three of such systems: the Fricke dosimeter (a sulfuric acid solution containing ferrous ions); an aerated neutral aqueous solution of methylene blue and neutral aerated water.

The experimental results are quantitatively comparable with the effect of pulse irradiation of high intensity (of the order $10^{23} \mathrm{eV} / \mathrm{ml} \cdot \mathrm{s}$ ) upon such systems. The highest limit of the "chemical efficiency» value of the investigated process may be considered to be $30-40 \%$. 